\title{
Associations of obesity with socioeconomic and lifestyle factors in middle-aged and elderly men: European Male Aging Study (EMAS)
}

\author{
T S Han, D M Lee ${ }^{1}$, M E J Lean², J D Finn³, T W O'Neill ${ }^{4}$, G Bartfai ${ }^{5}$, G Forti ${ }^{6}$, \\ A Giwercman7, K Kula ${ }^{8}$, N Pendleton ${ }^{9}$, M Punab $^{10}$, M K Rutter ${ }^{11,12,}$ \\ D Vanderschueren ${ }^{13}$, I T Huhtaniemi ${ }^{14}$, F C W Wu ${ }^{3}$, F F Casanueva ${ }^{15,16}$ and \\ the EMAS Study Group ${ }^{\dagger}$
}

Department of Endocrinology, Ashford and St Peter's NHS Foundation Trust, Surrey, UK, 'School of Social Sciences, Cathie Marsh Institute for Social Research, The University of Manchester, Manchester, UK, ${ }^{2}$ Department of Human Nutrition, University of Glasgow, Glasgow, UK, ${ }^{3}$ Andrology Research Unit and ${ }^{4}$ Arthritis Research UK Epidemiology Unit, Manchester Academic Health Science Centre, The University of Manchester, Manchester, UK, ${ }^{5}$ Department of Obstetrics, Gynaecology and Andrology, Albert Szent-György Medical University, Szeged, Hungary, ${ }^{6}$ Endocrinology Unit, University of Florence, Florence, Italy, ${ }^{7}$ Reproductive Medicine Centre, Skåne University Hospital, University of Lund, Lund, Sweden, ${ }^{8}$ Department of Andrology and Reproductive Endocrinology, Medical University of Łódź, Łódź, Poland, ${ }^{9}$ School of Community Based Medicine, Salford Royal NHS Trust, University of Manchester, Salford, UK, ${ }^{10}$ Andrology Unit, United Laboratories of Tartu University Clinics, Tartu, Estonia, ${ }^{11}$ The Endocrinology and Diabetes Research Group, Faculty of Medical and Human Sciences, Institute of Human Development, University of Manchester, Manchester, UK, ${ }^{12}$ Manchester Diabetes Centre, Manchester Academic Health Science Centre, Central Manchester University Hospitals NHS Foundation Trust, Manchester, UK, ${ }^{13}$ Department of Andrology and Endocrinology, Catholic University of Leuven, Leuven, Belgium, ${ }^{14}$ Department of Surgery and Cancer, Imperial College London, Hammersmith Campus, London, UK and ${ }^{15}$ Department of Medicine, Instituto Salud Carlos III, Complejo Hospitalario Universitario de Santiago (CHUS) and ${ }^{16}$ CIBER de Fisiopatologia Obesidad y Nutricion (CB06/03), Santiago de Compostela University, Santiago de Compostela, Spain

${ }^{+}$Details of the EMAS Study Group is given in the Acknowledgment section.

Correspondence should be addressed to F F Casanueva

Email

felipe.casanueva@usc.es

\section{Abstract}

Background: Social and lifestyle influences on age-related changes in body morphology are complex because lifestyle and physiological response to social stress can affect body fat differently.

Objective: In this study, we examined the associations of socioeconomic status (SES) and lifestyle factors with BMI and waist circumference (WC) in middle-aged and elderly European men.

Design and setting: A cross-sectional study of 3319 men aged 40-79 years recruited from eight European centres.

Outcomes: We estimated relative risk ratios (RRRs) of overweight/obesity associated with unfavourable SES and lifestyles.

Results: The prevalence of $\mathrm{BMI} \geq 30 \mathrm{~kg} / \mathrm{m}^{2}$ or $\mathrm{WC} \geq 102 \mathrm{~cm}$ rose linearly with age, except in the eighth decade when high BMI, but not high WC, declined. Among men aged 40-59 years, compared with non-smokers or most active men, centre and BMI-adjusted RRRs for having a WC between 94 and $101.9 \mathrm{~cm}$ increased by 1.6-fold in current smokers, 2.7-fold in least active men and maximal at 2.8-fold in least active men who smoked. Similar patterns but greater RRRs were observed for men with WC $\geq 102 \mathrm{~cm}$, notably 8.4 -fold greater in least active men who smoked. Compared with men in employment, those who were not in employment had increased risk of having a high WC by 1.4-fold in the 40-65 years group and by 1.3-fold in the 40-75 years group. These relationships were weaker among elderly men.

Conclusion: Unfavourable SES and lifestyles associate with increased risk of obesity, especially in middle-aged men. The combination of inactivity and smoking was the strongest predictor of high WC, providing a focus for health promotion and prevention at an early age. 


\section{Introduction}

Overweight and obesity continue to rise at alarming rates both in western and developing countries, imposing enormous burdens on social and health care systems. Drug prescribing costs are higher in almost all overweight/obese categories, and are twofold higher when comparing individuals with BMI values of 20 and $40 \mathrm{~kg} / \mathrm{m}^{2}(1,2)$. Associated with obesity and adverse body fat distribution are some specific clusters of symptoms and secondary chronic diseases, including coronary heart disease and type 2 diabetes mellitus $(3,4)$, which are exacerbated by smoking and physical inactivity and are most prevalent among those with lower socioeconomic status (SES). The relationship between alcohol consumption and adiposity remains unclear. Life-style factors vary between and within countries, but it is constantly found that poor lifestyles and socioeconomic deprivation are underlying drivers of the ever increasing prevalence in obesity in post-industrial societies, and this pattern arises rapidly with urbanisation in transitional countries.

Social and lifestyle influences on age-related changes in body morphology are complex because lifestyle and physiological response to social stress can affect body fat and skeletal muscle differently. The European Male Ageing Study (EMAS) collected health data from middle-aged and elderly men from eight European Centres, including anthropometry, socioeconomic and lifestyle factors as well as reported health status. The objectives of this study were to assess the associations of SES and lifestyle factors with BMI and waist circumference (WC) in middle-aged and elderly European men.

\section{Subjects and methods}

\section{Subjects and study design}

A total of 3319 men aged 40-79 years were recruited from population registers in eight European centres, five from non-transitional (Florence, Italy; Leuven, Belgium; Malmö, Sweden; Manchester, UK; Santiago de Compostela, Spain) and three from transitional countries (Łódź, Poland; Szeged, Hungary; Tartu, Estonia). Stratified random sampling was used, aiming to recruit equal numbers of men in each centre and into each decade (40-49, 50-59, 60-69, and 70-79 years). After completing a postal questionnaire including information about SES (peak education attainment and employment status) and lifestyle factors (smoking habits, alcohol consumption and physical activity level), the subjects attended research clinics for a health screen as previously described (5). Each participant completed interviewer-assisted questionnaires and underwent clinical assessments including anthropometry (weight, height, and WC). Ethics approval for the study was obtained in accordance with local institutional requirements in each centre and participants gave informed consent.

\section{Statistical analysis}

Statistical analyses were conducted using STATA SE version 13.1 (Stata Corp., College Station, TX, USA). The individuals were categorised according to their BMI $\left(<25,25-29.9\right.$ and $\left.\geq 30 \mathrm{~kg} / \mathrm{m}^{2}\right)$ or WC 'action levels' $(<94,94-101.9$, and $\geq 102 \mathrm{~cm})(6,7)$. For the purpose of this analysis, peak education attainment was classified as below high school, high school or college/university level; employment status as either employed or unemployment employment or non-employment; smoking status as never, former or current smokers; alcohol consumption as non-drinkers, infrequent alcohol drinkers (1-4 days/week) or frequent alcohol drinkers ( $\geq 5$ days/week); and physical activity according to quartiles of physical activity scale for the elderly (PASE) questionnaire score.

The prevalence of overweight and obesity based on BMI $25-29.9$ or $\geq 30 \mathrm{~kg} / \mathrm{m}^{2}$ and WC 94-101.9 or $\geq 102 \mathrm{~cm}$ in different categories of age, SES, and lifestyle factors was computed in all centres. $\chi^{2}$ test of independence was used to assess their associations. Linear regression analysis was used to determine the relationships between indices of adiposity and age. Multinomial logistic regression analysis was conducted to obtain the relative risk ratios (RRRs) to assess the likelihood that men with low SES or adverse lifestyle factors (predictor variables) would have a high BMI (25-29.9 or $\geq 30 \mathrm{~kg} / \mathrm{m}^{2}$ ) or a high WC (94-101.9 or $\geq 102 \mathrm{~cm}$ ) (dependent variables). A composite variable comprising a combination of modifiable lifestyle factors (smoking and physical activity) was created. Age and centre adjustment was made for relationships with both $\mathrm{BMI}$ and WC, as there were centre differences in the rates of obesity. In addition, adjustment for BMI and subgroup analysis stratified by age at 60 years was made for the relationship with WC. As we did not have reliable information on retirement status, we decided to classify subjects into employment and non-employment groups for men below 65 years old (working age in most 
countries). We assumed that the non-employment group comprises mostly men who were unemployed, with a smaller proportion who took early retirement. We also repeated this analysis for men below 75 years old to see if the outcome would differ from those below 65 years old as there would proportionally be more retired men (rather than unemployed) in the non-employment group.

\section{Results}

Table 1 shows that overall, high BMI $\left(\geq 30 \mathrm{~kg} / \mathrm{m}^{2}\right)$ or high WC $(\geq 102 \mathrm{~cm})$ was found in 25 and $35 \%$ of men respectively. There were 3\% of men with final education below high school level and 19\% below 65 years and $30.5 \%$ below 75 years not in employment, 21\% were

Table 1 Mean (S.D.) age and indices of adiposity and proportions of men in different categories of BMI, WC, socioeconomic status and lifestyle factors in European middleaged and elderly men $(n=3319)$.

\begin{tabular}{|c|c|}
\hline Characteristics & Values \\
\hline Age (years; mean (s.D.)) & $60.0(11.0)$ \\
\hline BMI $\left(\mathrm{kg} / \mathrm{m}^{2} ;\right.$ mean (s.D.)) & $27.7(4.1)$ \\
\hline WC (cm; mean (s.D.)) & $98.5(11.1)$ \\
\hline \multicolumn{2}{|l|}{ BMI $(n(\%))$} \\
\hline $\mathrm{BMI}<25 \mathrm{~kg} / \mathrm{m}^{2}$ & $870(26.3)$ \\
\hline Overweight $\left(25-29.9 \mathrm{~kg} / \mathrm{m}^{2}\right)$ & 1629 (49.2) \\
\hline Obesity $\left(\geq 30 \mathrm{~kg} / \mathrm{m}^{2}\right)$ & $814(24.6)$ \\
\hline \multicolumn{2}{|l|}{ WC $(n(\%))$} \\
\hline Below action level $1(<94 \mathrm{~cm})$ & $1142(34.4)$ \\
\hline Below action level 1-2 $(94-101.9 \mathrm{~cm})$ & $1006(30.3)$ \\
\hline Above action level $2(\geq 102 \mathrm{~cm})$ & $1171(35.3)$ \\
\hline \multicolumn{2}{|l|}{ Educational level $(n(\%))$} \\
\hline College/University & $1734(53.3)$ \\
\hline High school & $1428(43.9)$ \\
\hline Below high school & $93(2.9)$ \\
\hline \multicolumn{2}{|l|}{ Employment status (n (\%)) } \\
\hline Employment ( $<65$ years old $)$ & $1702(80.9)$ \\
\hline Non-employment ( $<65$ years old) & $401(19.1)$ \\
\hline Employment ( $<75$ years old) & 2061 (69.5) \\
\hline Non-employment $(<75$ years old $)$ & $906(30.5)$ \\
\hline \multicolumn{2}{|l|}{ Smoking habit $(n(\%))$} \\
\hline Never-smokers & $970(29.6)$ \\
\hline Former smokers & $1599(49.0)$ \\
\hline Current smokers & $693(21.2)$ \\
\hline \multicolumn{2}{|l|}{ Alcohol consumption (n (\%)) } \\
\hline Non-drinkers & $541(16.3)$ \\
\hline Infrequent drinkers (1-4 days/week) & $2010(60.7)$ \\
\hline Frequent drinkers ( $\geq 5$ days/week) & 759 (22.9) \\
\hline \multicolumn{2}{|l|}{ Physical level of activity (n (\%)) } \\
\hline High (PASE score quartile 4) & $776(24.9)$ \\
\hline Moderate (PASE score quartile 3 ) & $778(25.0)$ \\
\hline Low (PASE score quartile 2 ) & $779(25.0)$ \\
\hline Very low (PASE score quartile 1) & $778(25.0)$ \\
\hline Never-smokers and PASE quartile $4(n(\%))$ & $263(8.0)$ \\
\hline Former/current smokers and PASE quartile $1(n(\%))$ & $581(18.4)$ \\
\hline
\end{tabular}

PASE, Physical Activity Scale for the Elderly; WC, waist circumference. current smokers, 36\% drank frequently and 25\% had very low levels of physical activity.

The prevalence of obesity (BMI $\geq 30 \mathrm{~kg} / \mathrm{m}^{2}$ ) was significantly different across centres $(P<0.001)$ and generally lower in non-transitional countries $(17.1 \%$ in Florence, $19.8 \%$ in Leuven, $21.0 \%$ in Malmö, 21.3\% in Manchester and $27.2 \%$ in Santiago de Compostela) than transitional countries (21.9\% in Łódź, 35.2\% in Szeged, and $32.9 \%$ in Tartu).

Linear regression analysis revealed that age correlated weakly with $\mathrm{BMI}(P=0.03)$ (Fig. $1 \mathrm{~A})$ and more strongly with WC $(P=0.001)$ (Fig. 1B). Figure 2 shows that within each decade of age, the proportions of overweight men were consistently higher than the proportions of obese men. By contrast, there were higher proportions of men with WC above action level 2 ( $\geq 102 \mathrm{~cm})$ compared with those with WC between action level 1 and $2(94-101.9 \mathrm{~cm})$. This contrast was more evident in older men (age $\geq 60$ years). Figure 3A, B, C, D, and E represents the associations of adiposity with SES and lifestyle factors. There was a linear inverse trend in the prevalence of BMI between 25 and $29.9 \mathrm{~kg} / \mathrm{m}^{2}$ with education attainment, whilst the prevalence of BMI $\geq 30 \mathrm{~kg} / \mathrm{m}^{2}$ was observed to be higher among the men with middle-level education than those with either lowest or highest education (Fig. 3A). The prevalence of men with large waist (either $94-101.9 \mathrm{~cm}$ or $\geq 102 \mathrm{~cm}$ ) did not differ between educational levels. Figure 3B shows that BMI did not associate with employment status, whereas higher proportions of nonworking men had large WC than those who were in employment. Figure 3C shows that the prevalence of men with $\mathrm{BMI} \geq 30 \mathrm{~kg} / \mathrm{m}^{2}$ or with $\mathrm{WC} \geq 102 \mathrm{~cm}$ was highest among former smoking group. Figure 3D shows that the prevalence of men with BMI $\geq 30 \mathrm{~kg} / \mathrm{m}^{2}$ or men with WC $\geq 102 \mathrm{~cm}$ was higher in men who consumed alcohol $\leq 4$ days a week than those who consumed $\geq 5$ or more days a week. Figure 3E shows that the prevalence of men with $\mathrm{BMI} \geq 30 \mathrm{~kg} / \mathrm{m}^{2}$ was not significantly different across quartiles of physical activity, whilst the prevalence of men with WC $\geq 102 \mathrm{~cm}$ was greatest (44\%) in the lowest quartile (least active) and this prevalence decreases linearly with physical activity, being lowest (31\%) in the most active group of men (highest quartile).

Former/current smoking and physical inactivity were significantly more prevalent in men who achieved education below high school or were in the nonemployment category. Alcohol consumption was more frequent in men who were in employment (Supplementary Table 1, see section on supplementary data given at the end of this article). 

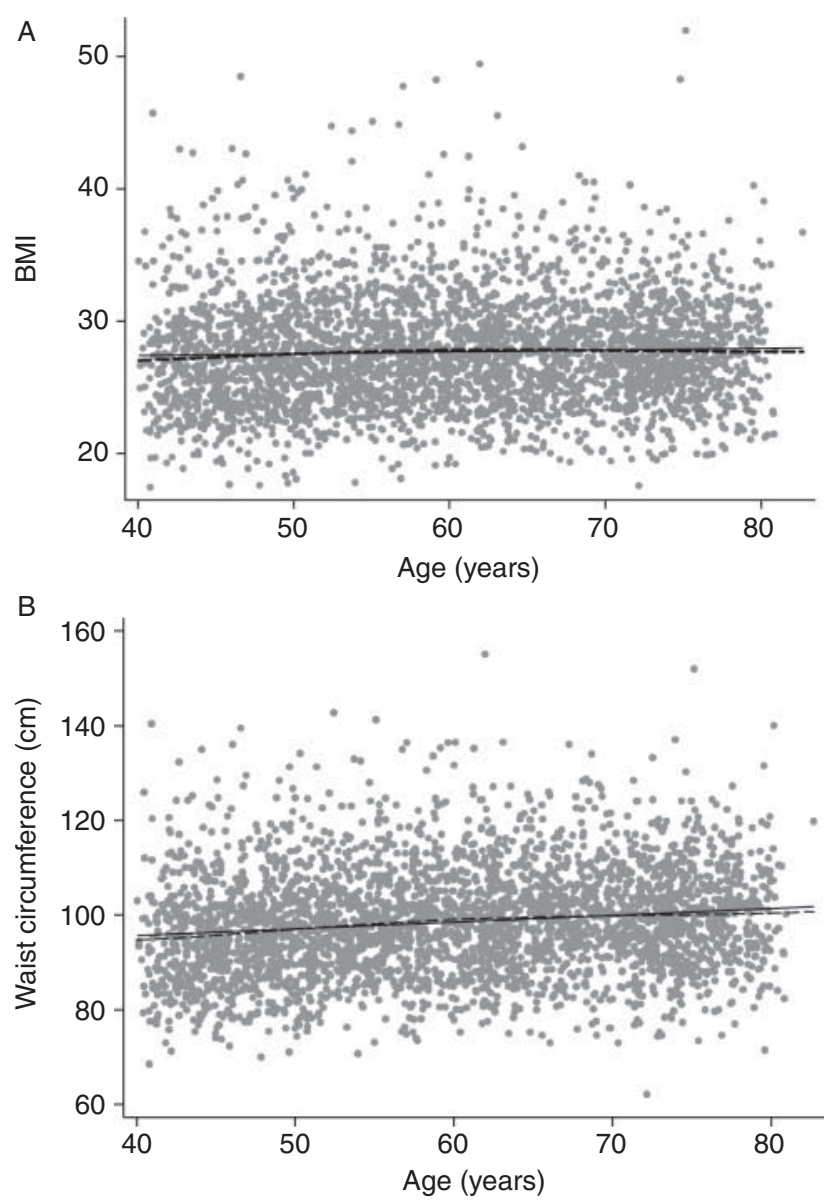

Figure 1

Association of age with (A) BMI and (B) waist circumference (WC). The solid lines represent the linear relationship and the dashed lines represent locally weighted scatterplot smoothing (LOWESS). Linear regression equations: $(A) B M I=26.8+0.014 \times$ age $(P=0.030)$, (B) WC $=89.9+0.143 \times$ age $(P=0.001)$.

Table 2 shows that when the analysis was adjusted for age and centre, compared with referent groups, there were greater RRRs for having a WC $\geq 102 \mathrm{~cm}$ in men who attained high school level of education by 1.3-fold and men who fell in the non-employment category by 1.4-fold in the below 65 years and 1.3-fold in the below 75 years. Compared with non-smokers, the RRR of having a WC $\geq 102 \mathrm{~cm}$ was higher by 1.6-fold in former smokers, but was not significantly different in current smokers. Compared with non-drinkers, men who drank alcohol up to 4 days a week had a 1.5-fold higher a RRR for having a WC between 94 and $101.9 \mathrm{~cm}$, whereas there was a lower RRR (0.74, CI: 0.56, 0.98) for having a high WC in men who drank frequently ( $\geq 5$ days/week), but these associations disappeared after adjustment for BMI was made.
This pattern largely persisted when subjects were analysed separately in each centre. The RRR for having a WC $\geq 102 \mathrm{~cm}$ was higher by 2.1-fold in former/current smokers and least physically active men. Additional adjustment for BMI showed that the RRR for having high a WC between 94 and 101.9 was greater by 1.4-fold amongst current smokers or in men who achieved lower level of physical activity - by 1.7-fold in the lowest PASE quartile. The RRR for having a WC $\geq 102 \mathrm{~cm}$ was greater by 2.2-fold in current smokers, 1.8-fold, 1.7-fold, and 3.9-fold in men whose physical activity level was in quartile 3, 2, and 1 respectively. Amongst men who both smoked (former/current) and least physically active, the RRRs of having a WC between 94 and 101.9 or WC $\geq 102 \mathrm{~cm}$ were higher by 2.2- or 5.1-fold respectively. The association between BMI, SES and lifestyle factors was much weaker (Supplementary Table 2).

Table 2 shows that within the 40-59 age band, compared with referent groups, the age, centre, and BMIadjusted RRR for having a WC between 94 and $101.9 \mathrm{~cm}$ was 1.6-fold higher in current smokers, and 2.7-fold higher in men reporting the lowest physical activity levels (PASE quartile 1). This risk was numerically higher (2.8-fold higher than referent) in men who both smoked and were least physically active. Similar patterns but greater RRRs were observed for having a WC $\geq 102 \mathrm{~cm}$ in men with low SES and adverse lifestyle factors; notably an 8.4-fold higher risk was observed in men who were current smokers and were least physically active. Within the 60-79 age band, compared with referent groups, the risk for having a WC between 94 and 101.9 or $\geq 102 \mathrm{~cm}$ was lower and less frequently observed in relation with poor lifestyle

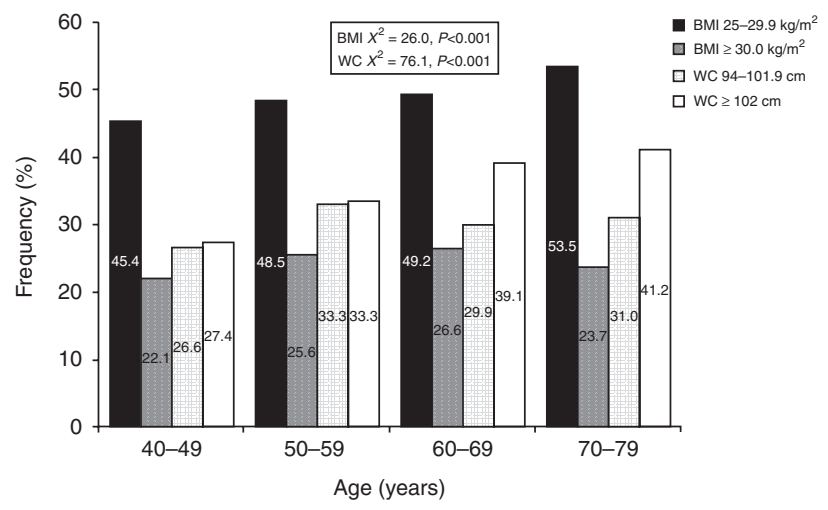

Figure 2

Distribution of subjects with high BMI $\left(25-29.9 \mathrm{~kg} / \mathrm{m}^{2}\right.$ or $\geq 30 \mathrm{~kg} / \mathrm{m}^{2}$ ) or high waist circumference $(94-101.9 \mathrm{~cm}$ or $\geq 102 \mathrm{~cm}$ ) by 10 -year age groups. 


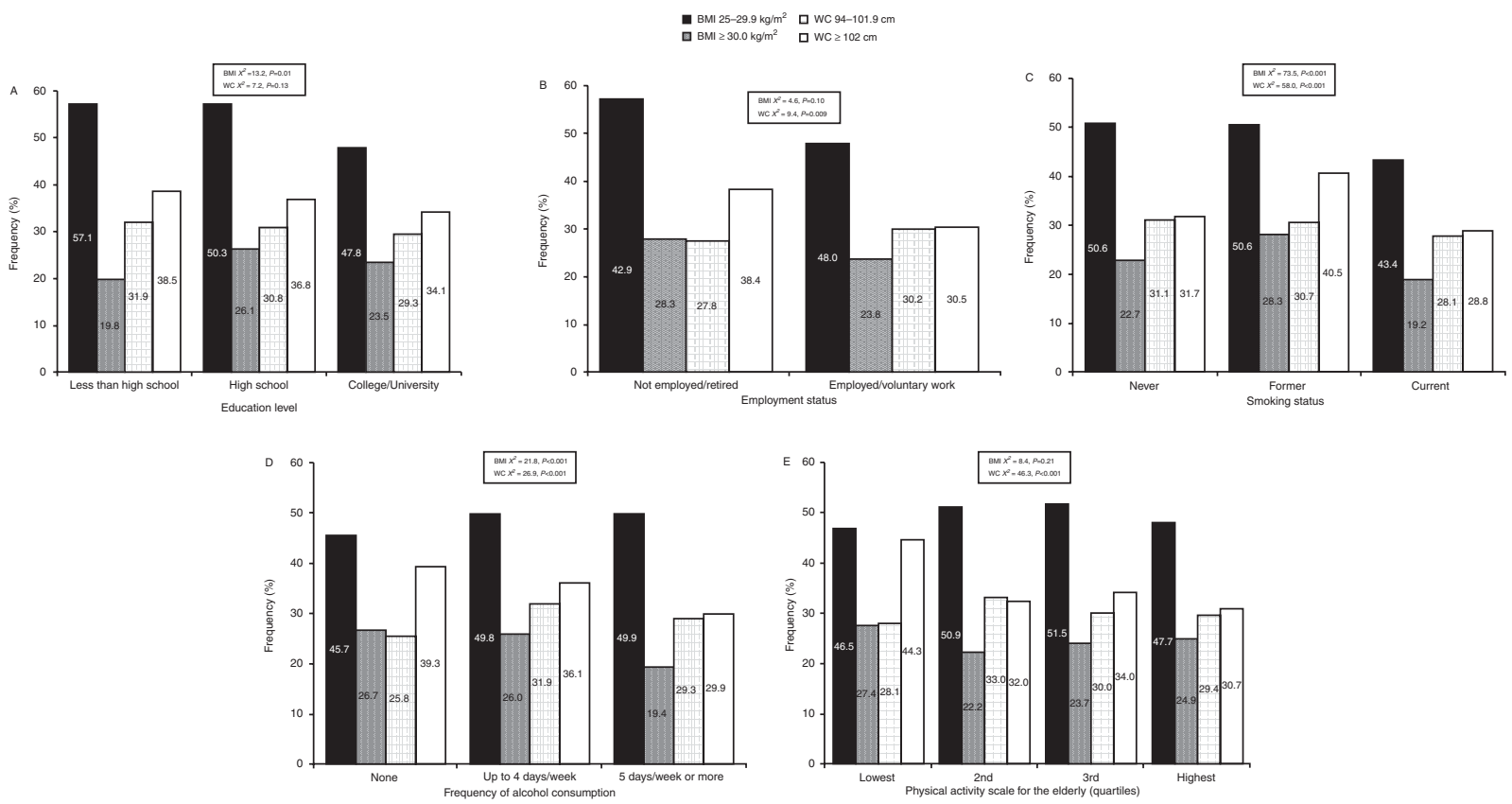

\section{Figure 3}

Proportions of men with high BMI ( $\geq 30 \mathrm{~kg} / \mathrm{m}^{2}, n=814$ ) or high waist circumference $(\geq 102 \mathrm{~cm}, n=1171)$ in different categories of (A) education level, (B) employment status ( $<65$ years old), (C) smoking habits, (D) alcohol consumption, and (E) physical activity.

factors than that observed in younger men (vida supra). In this older age band, the risk of having a WC $\geq 102 \mathrm{~cm}$ was 3.5-fold higher in the least active men, and this risk was 5.5-fold higher than referent group in those that both smoked and were least physically active.

There were $66 \%$ of men with WC $<94 \mathrm{~cm}$ and BMI $<25 \mathrm{~kg} / \mathrm{m}^{2}$, whilst $64 \%$ of men with WC $\geq 102 \mathrm{~cm}$ had BMI $\geq 30 \mathrm{~kg} / \mathrm{m}^{2}$. In contrast, $87 \%$ of men with BMI $<25 \mathrm{~kg} / \mathrm{m}^{2}$ had WC $<94 \mathrm{~cm}$ whilst $91 \%$ of men with BMI $\geq 30 \mathrm{~kg} / \mathrm{m}^{2}$ had WC $\geq 102 \mathrm{~cm}$. There were $<1 \%$ of men with a combination of WC $<94 \mathrm{~cm}$ and $\mathrm{BMI} \geq 30 \mathrm{~kg} / \mathrm{m}^{2}$, or WC $\geq 102 \mathrm{~cm}$ and BMI $<25 \mathrm{~kg} / \mathrm{m}^{2}$, and similarly a combination of BMI $<25 \mathrm{~kg} / \mathrm{m}^{2}$ and $\mathrm{WC} \geq 102 \mathrm{~cm}$ or BMI $\geq 30 \mathrm{~kg} / \mathrm{m}^{2}$ and $\mathrm{WC}<94 \mathrm{~cm}$.

\section{Discussion}

This study has shown that the prevalence of obesity increased with age, but in the oldest group, the prevalence of high BMI declined whilst high WC continued to rise. Low SES as well as modifiable lifestyle factors was associated with higher risk of large WC, more strongly in middle-aged men even after adjusting for BMI.

In this study, the prevalence of high WC was only observed in men in the oldest decade, whilst a drop in the prevalence of high BMI probably reflects a loss of total lean mass in older men who continue to accumulate fat, and may shift its distribution to a more central, intraabdominal deposition. This change has been described previously and interpreted as an age-related trend towards sarcopenia, which is associated with loss of physical function and a range of co-morbidities (8). These findings are important when adiposity is measured in the elderly populations as BMI is likely to underestimate their body fatness. WC appears to be a better adiposity index through all ages (9), and older men with large WC appear to be at greater risk of many disease outcomes (10). These findings support the Rotterdam Study (11), which showed that high WC, but not BMI, predicted mortality in older men. Prevention of weight gain at earlier ages may reduce multiple adverse health consequences.

Our findings of higher risk of high WC among men who were not in employment were consistent with previous studies showing that obesity is more prevalent in people with low SES $(12,13)$, compounding health inequality. Poor lifestyle such as high-fat diets and lack of exercise as well as social stress may explain this association $(14,15)$. Areas of low SES harbours poorer food quality, where there is a focus on cheaper processed fast foods which outsell fresh fruit and vegetables $(16,17)$. 


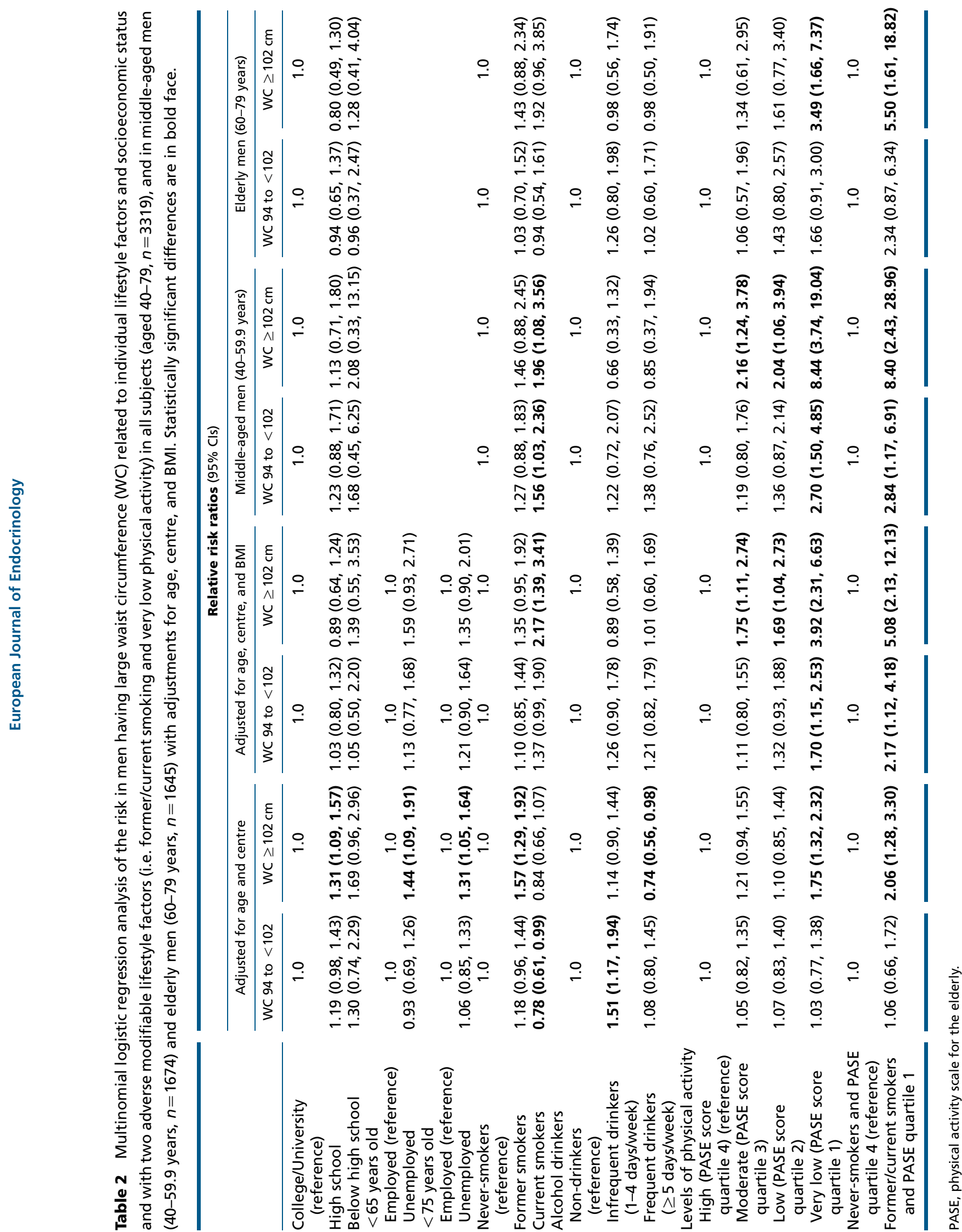


We found the men in lower SES were more likely to be smokers or sedentary while more frequent drinkers were found among men who were working.

Our study did not have reliable information on retirement; therefore, we classified men below 65 years old into employment and non-employment groups. There were $81 \%$ of men in employment and $19 \%$ in unemployment (unemployed plus retired men). These figures are similar to the MORGEN study of 5733 Dutch men below 65 years old, showing $78.6 \%$ of men in employment and $18.1 \%$ in unemployment (12.6\% unemployed and $7.5 \%$ retired early) (8). The MORGEN study has shown that men who retired early, and similarly men in employment, had a lower risk of high WC than unemployed men (8), suggesting that RRRs for having high WC in the nonemployment group in our study would likely to be greater if retired men were excluded, i.e. leaving only unemployed men in the non-employment group. Our study has also shown that RRRs for having high WC or BMI in the nonemployment group did not differ substantially whether the cut off at 65 or 75 years was used, suggesting that the age of retirement had little effect on obesity.

This study has shown that modifiable lifestyle factors all associate consistently with greater risk of large WC irrespective of BMI. The high proportion of men with large WC in former smokers may reflect men who gave up smoking due to poor health and are also least physically active. These relationships were less apparent with BMI. Greater WC and BMI have previously been reported in former smokers $(18,19)$. The association of high WC with physical inactivity seems obvious, whereas that of high WC and smoking do not. Although current smokers were at reduced risk of high BMI, they were at increased risk of having high WC (after BMI adjustment), indicating the adverse effects of smoking on changes in body morphology - losing muscle mass while accumulating abdominal fat. A study of rats by Liu et al. (20) has found that ubiquitin-specific protease-19 (an enzyme involved in removal of ubiquitin from specific target proteins for cellular processes by tagging them for degradation) was upregulated with muscle atrophy on exposure to chronic cigarette smoke, and that cigarette smoke extract promoted myotube wasting in vitro by inhibiting myogenic differentiation and acted via phosphorylated MAPKs to stimulate the expression of ubiquitin-specific protease-19. How cigarette smoke promotes increased abdominal fat accumulation remains unclear.

The association between lower alcohol intake frequency and obesity seems paradoxical and may be explained by a number of ways including affordability and under-reporting, as well as quality of drink, but this information was not available in this study. Another possibility is those who reported drinking the least amount of alcohol presently, associated with greater WC or BMI, may be less healthy if they included abstinence. We found that those who were drinking $\leq 4$ days/week were not associated with SES but tended to be less active and former/current smokers. Another possible explanation is that the frequency of alcohol consumption may not reflect total amounts because binge drinking may fall in the low frequency category and these habits may vary between centres. We did not collect information on binge drinking in this study. A thorough review of the literature and how data analyses from the UK were performed has suggested that the amount of alcohol consumed and the frequency of consumption may be disconnected and have opposite influence on adiposity (21).

The present analysis has shown that when BMI or WC alone was related with adverse SES and lifestyle factors, few significant relationships were observed. The relationships were revealed when WC was adjusted for BMI, showing how adverse lifestyle factors such as physical inactivity and smoking were associated with greater WC. Previous studies have demonstrated that WC predicts mortality more strongly after adjustment for BMI (22). However, it is difficult to interpret these associations, as WC and BMI are highly correlated $(r=0.894, P<0.001)$ and both are similar predictors of total body fat, while BMI is also influenced by muscle mass (23). A possible explanation could be that by adjusting for BMI, the muscle component is eliminated. This concept is supported by the strengthening of the relationship between high WC and physical inactivity or smoking (both factors lead to muscle atrophy) when BMI was taken into account in this study.

Interesting findings emerged in this study with regard to age. Physical inactivity and smoking were associated with high WC more strongly in middle-aged men than in older men. These differences may be explained by selection or survivor bias - older men with large WC may have poor health that prevents them from participating in the study. Another possible explanation is that lifestyles may exert stronger influences on WC in younger than older men, resulting in more distinct differences between low WC and high WC among younger men. Based on this evidence, we suggest the practice of healthy lifestyles from early age order to prevent obesity, particularly high WC.

The present data add to current concern that BMI is not the best simple indicator of adiposity or of disease risk. 
WC is a better indicator of total body fat than BMI. The lowest category of WC contained only $66 \%$ men with BMI in the lowest category while the other 33\% had BMI between 25 and $29.9 \mathrm{~kg} / \mathrm{m}^{2}$. This is probably due to a number of men whose BMI reflected muscularity rather than overweight. Conversely, only $64 \%$ men with BMI $\geq 30 \mathrm{~kg} / \mathrm{m}^{2}$ fell with the highest WC category. This may indicate that the $36 \%$ with BMI $25-29.9 \mathrm{~kg} / \mathrm{m}^{2}$ within highest category were associated with muscle atrophy.

The main strengths of EMAS are a large communitybased sample and use of uniform methods to assess adiposity, lifestyle factors and potential confounders. Although limitations of the study have been described previously (5), certain factors need to be highlighted in this study. We enrolled mainly Caucasian men with a study response rate of $41 \%$, which could limit generalisability. Those who participated may have differed with respect to SES, lifestyle factors and anthropometric measures from those who did not participate, thus some caution is needed in the interpretation of the data. Small proportions of subjects appeared in some categories, such as those with an educational attainment below high school level, potentially introducing bias in these results. The main findings, however, were based on an internal comparison of responders, and therefore any selection factors were unlikely to have had any important effect on these data. The cross-sectional design precluded study of the temporal nature of associations, for which prospective data are required.

In conclusion, unfavourable SES and poor lifestyles were associated with risk of obesity, with greater impact on WC than BMI, especially in middle-aged men. The combination of inactivity and smoking was the strongest predictor of high WC, providing a focus for health promotion and prevention at an early age.

\section{Supplementary data}

This is linked to the online version of the paper at http://dx.doi.org/10.1530/ EJE-14-0739.

\section{Declaration of interest}

The authors declare that there is no conflict of interest that could be perceived as prejudicing the impartiality of the research reported.

\section{Funding}

The European Male Ageing Study (EMAS) is funded by the Commission of the European Communities Fifth Framework Programme 'Quality of Life and Management of Living Resources' Grant QLK6-CT-2001-00258. F C W $\mathrm{Wu}$ is a consultant for GSK, Bayer-Schering, Jenapharm, Ferring, TAP,
Lilly-ICOS, Proctor and Gamble, Ardana Biosciences, Pierre Fabre Medicaments, Acrux DDS Pty Ltd, and has also chaired advisory board meetings and lectured on their behalf. F C W Wu has received lecture fees from Organon, Bayer-Schering, Lilly-ICOS, Ardana Biosciences, Pierre Fabre Medicaments. F C W Wu has received grant support (2009-2013) from Bayer-Schering AG and the New England Research Institute, Watertown, MA, USA. I T Huhtaniemi is a consultant and has received grants from Ferring Pharmaceuticals.

\section{Acknowledgements}

The authors wish to thank the participants in the eight countries and research/nursing staff in the eight centres: C Pott (Manchester), E Wouters (Leuven), M Nilsson (Malmö), M del Mar Fernandez (Santiago de Compostela), M Jedrzejowska (Łódź), H -M Tabo (Tartu), A Heredi (Szeged) for their meticulous data collection and C Moseley (Manchester) for data entry and project co-ordination. The EMAS Study Group: Florence (G Forti, Luisa Petrone, and Giovanni Corona); Leuven (D Vanderschueren and Herman Borghs); Łódź (K Kula, Jolanta Slowikowska-Hilczer, and Renata Walczak-Jedrzejowska); London (I T Huhtaniemi); Malmö (A Giwercman); Manchester (F C W Wu, Alan Silman, T W O'Neill, J D Finn, Philip Steer, and Stephen Pye); Santiago (F F Casanueva, and Ana I Castro); Szeged (G Bartfai, Imre Földesi, and Imre Fejes); Tartu (M Punab and Paul Korrovitz).

\section{References}

1 Counterweight Project Team. Influence of body mass index on prescribing costs and potential cost savings of a weight management programme in primary care. Journal of Health Services Research \& Policy 200813 158-166. (doi:10.1258/jhsrp.2008.007140)

2 Tigbe WW, Briggs AH \& Lean ME. A patient-centred approach to estimate total annual healthcare cost by body mass index in the UK Counterweight programme. International Journal of Obesity 201337 1135-1139. (doi:10.1038/ijo.2012.186)

3 Casanueva FF, Moreno B, Rodríguez-Azeredo R, Massien C, Conthe P, Formiguera X, Barrios V \& Balkau B. Relationship of abdominal obesity with cardiovascular disease, diabetes and hyperlipidaemia in Spain. Clinical Endocrinology 201073 35-40. (doi:10.1111/j.1365-2265. 2009.03727.x)

4 Caterson ID, Hubbard V, Bray GA, Grunstein R, Hansen BC, Hong Y, Labarthe D, Seidell JC, Smith SC Jr \& American Heart Association. Prevention conference VII: obesity, a worldwide epidemic related to heart disease and stroke: group III: worldwide comorbidities of obesity. Circulation 2004110 e476-e483. (doi:10.1161/01.CIR.0000140114. 83145.59)

5 Lee DM, O'Neill TW, Pye SR, Silman AJ, Finn JD, Pendleton N, Tajar A, Bartfai G, Casanueva F, Forti G et al. The European Male Ageing Study (EMAS): design, methods and recruitment. International Journal of Andrology 200932 11-24. (doi:10.1111/j.1365-2605.2008.00879.x)

6 Lean ME, Han TS \& Morrison CE. Waist circumference as a measure for indicating need for weight management. BMJ 1995311 158-161. (doi:10.1136/bmj.311.6998.158)

7 National Cholesterol Education Program (NCEP) Expert Panel on Detection, Evaluation, and Treatment of High Blood Cholesterol in Adults (Adult Treatment Panel III). Third Report of the National Cholesterol Education Program (NCEP) Expert Panel on Detection, Evaluation, and Treatment of High Blood Cholesterol in Adults (Adult Treatment Panel III) final report. Circulation 2002106 3143-3421.

8 Han TS, Bijnen FC, Lean ME \& Seidell JC. Separate associations of waist and hip circumference with lifestyle factors. International Journal of Epidemiology 199827 422-430. (doi:10.1093/ije/27.3.422) 
9 Vlassopoulos A, Combet E \& Lean ME. Changing distributions of body size and adiposity with age. International Journal of Obesity $2013 \mathbf{3 8}$ 857-864. (doi:10.1038/ijo.2013.216)

10 Moore LL, Bradlee ML, Singer MR, Splansky GL, Proctor MH, Ellison RC $\&$ Kreger BE. BMI and waist circumference as predictors of lifetime colon cancer risk in Framingham Study adults. International Journal of Obesity 200428 559-567. (doi:10.1038/sj.ijo.0802606)

11 Visscher TL, Seidell JC, Molarius A, van der Kuip D, Hofman A \& Witteman JC. A comparison of body mass index, waist-hip ratio and waist circumference as predictors of all-cause mortality among the elderly: the Rotterdam study. International Journal of Obesity 200125 1730-1735. (doi:10.1038/sj.ijo.0801787)

12 Chen R \& Tunstall-Pedoe H. Socioeconomic deprivation and waist circumference in men and women: the Scottish MONICA surveys 1989-1995. European Journal of Epidemiology 200520 141-147. (doi:10.1007/s10654-004-4498-y)

13 Drewnowski A \& Specter SE. Poverty and obesity: the role of energy density and energy costs. American Journal of Clinical Nutrition 2004 79 6-16.

14 Pampel FC, Krueger PM \& Denney JT. Socioeconomic disparities in health behaviors. Annual Review of Sociology 201036 349-370. (doi:10.1146/annurev.soc.012809.102529)

15 Burns CM, Gibbon P, Boak R, Baudinette S \& Dunbar JA. Food cost and availability in a rural setting in Australia. Rural and Remote Health 2004 4311.

16 Burns CM \& Inglis AD. Measuring food access in Melbourne: access to healthy and fast foods by car, bus and foot in an urban municipality in Melbourne. Health \& Place 200713 877-885. (doi:10.1016/j.healthplace.2007.02.005)
17 Smoyer-Tomic KE, Spence JC, Raine KD, Amrhein C, Cameron N, Yasenovskiy V, Cutumisu N, Hemphill E \& Healy J. The association between neighborhood socioeconomic status and exposure to supermarkets and fast food outlets. Health \& Place 200814 740-754. (doi:10.1016/j.healthplace.2007.12.001)

18 Akbartabartoori M, Lean ME \& Hankey CR. Relationships between cigarette smoking, body size and body shape. International Journal of Obesity 200529 236-243. (doi:10.1038/sj.ijo.0802827)

19 Slagter SN, van Vliet-Ostaptchouk JV, Vonk JM, Boezen HM, Dullaart RP, Kobold AC, Feskens EJ, van Beek AP, van der Klauw MM \& Wolffenbuttel BH. Associations between smoking, components of metabolic syndrome and lipoprotein particle size. BMC Medicine 2013 11 195. (doi:10.1186/1741-7015-11-195)

20 Liu Q, Xu WG, Luo Y, Han FF, Yao XH, Yang TY, Zhang Y, Pi WF \& Guo XJ. Cigarette smoke-induced skeletal muscle atrophy is associated with up-regulation of USP-19 via p38 and ERK MAPKs. Journal of Cellular Biochemistry 2011112 2307-2316. (doi:10.1002/jcb.23151)

21 Vlachou P, Lean M \& McLoone P. Associations between reported alcohol consumption and body composition in Scottish adults. Obesity Facts 20136 (Suppl 1) T3T4:P.096 207.

22 Bigaard J, Tjønneland A, Thomsen BL, Overvad K, Heitmann BL \& Sørensen TI. Waist circumference, BMI, smoking, and mortality in middle-aged men and women. Obesity Research 200311 895-903. (doi:10.1038/oby.2003.123)

23 Seidell JC, Björntorp P, Sjöström L, Sannerstedt R, Krotkiewski M \& Kvist H. Regional distribution of muscle and fat mass in men - new insight into the risk of abdominal obesity using computed tomography. International Journal of Obesity 198913 289-303.

Received 29 August 2014

Revised version received 1 October 2014

Accepted 17 October 2014 